\title{
A Dopamine Sensor Based on Pre-Concentration by Magnetic Nanoparticles
}

\author{
Mojtaba Bagherzadeh, ${ }^{1}$ Somayeh Ansari, ${ }^{2}$ Fariborz Riahi, ${ }^{1}$ and Anahita Farahbakhsh ${ }^{2}$ \\ ${ }^{1}$ Material Research School, NSTRI, Isfahan 81465-1589, Iran \\ ${ }^{2}$ Islamic Azad University, Shahreza Branch, Shahreza 86145-311, Iran \\ Correspondence should be addressed to Mojtaba Bagherzadeh; mjmo123@yahoo.com
}

Received 30 April 2013; Revised 11 August 2013; Accepted 20 August 2013

Academic Editor: Shen-Ming Chen

Copyright (c) 2013 Mojtaba Bagherzadeh et al. This is an open access article distributed under the Creative Commons Attribution License, which permits unrestricted use, distribution, and reproduction in any medium, provided the original work is properly cited.

Herein, $\mathrm{Fe}_{3} \mathrm{O}_{4}$ magnetic nanoparticles (MNPs) were synthesized and characterized. Afterward, a magnetic carbon paste electrode (MCPE) was modified with MNPs via casting and drying MNPs on top of the MCPE (MCPE/MNP). Electrochemical behavior of the MCPE/MNP was studied by cyclic voltammetry in the presence of $\left[\mathrm{Fe}(\mathrm{CN})_{6}\right]^{3-/ 4-}$ as a redox probe, and surface $\mathrm{p} K_{a}$ of $\mathrm{MNPs}$ was evaluated as $6.3 \pm 0.1$. The behavior of MCPE/MNP towards dopamine (DA) and ascorbic acid (AA) has been investigated by electrochemical methods, and the obtained results showed that the MCPE/MNP has adsorption behavior towards only DA. Based on this behavior, the DA molecules were pre-concentrated on top of the MCPE/MNP and followed with stripping in DA free solution. Subsequent to experimental and instrumental optimization, a calibration curve from $5.0 \times 10^{-6}$ to $1.0 \times 10^{-3} \mathrm{M} \mathrm{DA}$ with $r^{2}=0.999, \mathrm{DL}=7.6 \times 10^{-7} \mathrm{M} \mathrm{DA}$, and $\mathrm{RSD}=4.6 \%$, was obtained in the presence of $1.0 \times 10^{-3} \mathrm{M}$ AA. Performance of the $\mathrm{MCPE} / \mathrm{MNP}$ was successfully tested in a pharmaceutical sample.

\section{Introduction}

Dopamine (DA) is one of the most important neurotransmitters. It plays a significant role in the functioning of central nervous, renal, and hormonal systems as well as in drug addiction and Parkinson's disease $[1,2]$. Therefore, understanding its electrochemical properties and quantifying its presence in human body fluids are the most important. Dopamine can be easily oxidized electrochemically at conventional electrodes, which have been used to detect the neurotransmitter [3-7]. Apart from the need to reach low detection limits, determination of the DA is complicated by the coexistence of many interfering compounds. Among them, ascorbic acid (AA) is of particular importance [8]. Ascorbic acid accompanies DA in biological samples: for instance, in the extracellular fluid of central nervous system, AA is present at the 100-500 $\mu \mathrm{M}$ concentration level, whereas the concentration of DA is less than $100 \mathrm{nM}$ [9]. But, in the biological samples, the basic concentrations of DA and AA vary from region to region and time to time in an extremely wide range, from $1.0 \times 10^{-7}$ to $1.0 \times 10^{-3} \mathrm{M}[10]$. Therefore, improving the sensitivity and especially the selectivity of working electrodes toward the DA has been a goal of researchers in this area. To meet this challenge, a variety of modified electrodes have been proposed. These include self-assembled monolayer electrodes [5-7], polymer electrodes [11, 12], and nanomaterial film electrodes [13-15]. However, in all cases two general strategies were employed for detection of DA; (i) separation of DA and AA oxidation potentials, or (ii) selective preconcentration of DA and following its determination [16].

Materials in the nanometer range are expected to exhibit new functional properties for a wide range of applications, including: catalysis, optics, microelectronics, and chemical/ biological aspects. One of the most interesting and practically promising fields is the research on magnetic nanoparticles for their attractive properties and many potential applications as sensors technology [17]. Recently, ferromagnetic materials have gained much intense research on biomedical and biotechnological applications. Superparamagnetic iron oxide nanoparticle $\left(\mathrm{Fe}_{3} \mathrm{O}_{4}\right)$ is one of the famous magnetic materials in common use. Due to its biocompatibility, catalytic activity, and low toxicity, its applications in biotechnology 
and medicine have gained significant attention, and it would be promising to utilize $\mathrm{Fe}_{3} \mathrm{O}_{4}$ nanoparticles for the sensing application [18]. It has been reported that these kinds of particles could be functionalized with a wide range of functional groups [19-22] and favorably interacted with enzymes by some active groups such as $-\mathrm{OH},-\mathrm{COOH}$, and $-\mathrm{NH}_{2}$ [23]. So it is of interest to examine the interaction of biologically active molecules such as DA by ferromagnetic nanoparticles. There are few reports on the electrochemical study of $\mathrm{Fe}_{3} \mathrm{O}_{4} \mathrm{MNPs}$ interaction with DA [24-26]. In all reported works, $\mathrm{Fe}_{3} \mathrm{O}_{4}$ MNPs were employed in determination of DA via strategy (i), that is, oxidation potential separation. On the other hand, recently interest reports were published on bonding DA to the $\mathrm{Fe}_{3} \mathrm{O}_{4}$ MNPs via its diols [27-31]. However, this interesting behavior did not employ in dopamine determination via strategy (ii), that is, selective pre-concentration of DA.

In the present work, $\mathrm{Fe}_{3} \mathrm{O}_{4}$ nanoparticles have been synthesized and characterized, and then its dispersing solution was casted on the magnetic CPE to form a novel modified electrode (MCPE/MNP). The experimental results showed that the modified electrodes displayed a significant promoting effect on the oxidation of $\left[\mathrm{Fe}(\mathrm{CN})_{6}\right]^{3-/ 4-}$ as a redox probe with the remarkable enhancement in the peak current. Effects of scan rate and $\mathrm{pH}$ were evaluated on the MCPE/MNP response to the redox probe, and surface area and charge state (surface $\mathrm{p} K_{a}$ ) of the MCPE/MNP were calculated from its response. Interaction of the $\mathrm{Fe}_{3} \mathrm{O}_{4} \mathrm{MNP}$ with DA molecules was studied by electrochemical and spectroscopic methods, and an adsorption behavior was observed and confirmed. This adsorption behavior of DA allowed us to pre-concentrate DA on top of the MCPE/MNP surface from solution. Effective parameters such as $\mathrm{pH}$, pre-concentration time, amount of $\mathrm{Fe}_{3} \mathrm{O}_{4}$, and instrumental parameters on adsorbed DA response were evaluated. Finally, the performance of the MCPE/MNP was successfully examined for electrochemical determination of DA in a pharmaceutical sample. Recently, Liu et al. reported the first example of the quantification of DA using $\mathrm{Fe}_{3} \mathrm{O}_{4}$ nanoparticles via fluorescence spectroscopy [32], but the current work is an example of electrochemical determination of DA by using $\mathrm{Fe}_{3} \mathrm{O}_{4}$ MNPs based on selective pre-concentration of DA, that is, strategy (ii). The obtained results will be presented and described here.

\section{Experimental}

2.1. Chemicals. Dopamine, ascorbic acid, and other materials were of analytical grade (Sigma or Merck) and were used as received without further purifying. $\mathrm{Fe}_{3} \mathrm{O}_{4}$ magnetic nanoparticles were prepared according to the literature [33]. Graphite powder (spectrum grade, average particle size $4 \mu \mathrm{m}$ ) and paraffin oil were from Merck. Phosphate buffer saline solutions (PBS) in the $\mathrm{pH}$ range of 2.0 to 10.0 were prepared using Smalley's method [34]. The initial $\mathrm{pH}$ was ca. 2.1 for $0.1 \mathrm{M}$ $\mathrm{NaClO}_{4}+0.01 \mathrm{M} \mathrm{H}_{3} \mathrm{PO}_{4}$. The higher $\mathrm{pH}$ was adjusted by the addition of $0.11 \mathrm{M} \mathrm{NaOH}$. The ionic strength of the solutions was constant over the entire range of $\mathrm{pH}$. A DOPADIC ampoule (Iran Pharmaceutical Development Investment Co., I.P.D.I.C., Rasht, Iran) containing $5 \mathrm{~mL}$ of $200 \mathrm{mg} \mathrm{mL}^{-1}$ DA hydrochloride was used as DA source of pharmaceutical sample.

2.2. Electrode Preparation. The conventional carbon paste was prepared by mixing $70 \mathrm{mg}$ graphite powder and $30 \mu \mathrm{L}$ paraffin oil. A magnetic carbon paste electrode (MCPE) consisted of a permanent cylinder magnet $(5 \mathrm{~mm} \mathrm{~d} . \times 2 \mathrm{~mm} \mathrm{l}$.) and was press-fit into a syringe cylindrical tube $(6 \mathrm{~mm}$ o.d. $\times$ $50 \mathrm{~mm} \mathrm{l}$.). The magnet was connected to a copper wire for electrical connection on one end. On the other end, it was packed with carbon paste to about $2 \mathrm{~mm}$ depth from the liquid interface. The surface of carbon paste was smoothed on a weighing paper for the MCPE, and the surface area of $0.12 \mathrm{~cm}^{2}$ was calculated based on Randle-Sevcik equation [35]. One hundred mg of nanosized $\mathrm{Fe}_{3} \mathrm{O}_{4}$ particles were dispersed in $10 \mathrm{~mL}$ ethanol under ultrasonication for $30 \mathrm{~min}$. Six $\mu \mathrm{L}$ of this dispersion solution was chosen as the modifying amount and dropped onto the surface of the MCPE, then dried in air at room temperature for forming the modified electrode (MCPE/MNP).

2.3. Instruments. The crystal structure of the as-prepared $\mathrm{Fe}_{3} \mathrm{O}_{4}$ powders was studied by an X-ray diffractometer (XRD, Bruker Advanced D8 model), using $\mathrm{Cu} \mathrm{K}_{\alpha}$ radiation $(\lambda=$ $1.5406 \AA$ ). The size and morphology of the as-prepared $\mathrm{Fe}_{3} \mathrm{O}_{4}$ particles and the chemical composition of the prepared particles were characterized using transmission electron microscope, TEM, (Philips-EM-208S) and scanning electron microscope, SEM, (Seron Technology AIS 2100 (South Korea)) equipped EDXA instruments. Magnetic properties were analyzed using a vibrating sample magnetometer (VSM, Daghigh Meghnatis Kashan Co., Kashan, Iran). The specific surface areas of MNPs were determined by the BET method. Fourier-transform infrared (FTIR) spectroscopy analysis was performed with a Nicolet Impact 400D Model spectrophotometer (Nicolet Impact, Madison, USA). Instruments UVVis detection was carried out on a double beam UV-Vis spectrometer (Cintra 404, GBC).

All electrochemical measurements including cyclic voltammetry (CV) and square wave voltammetry (SWV) were carried out on Metrohm 797VA instrument (Herisau, Switzerlan). A three-electrode conventional cell, including the modified MCPE as working electrode, a large surface area Pt plate (99.99\%) as auxiliary electrode, and a $\mathrm{Ag} / \mathrm{AgCl}(3 \mathrm{M} \mathrm{KCl})$ electrode as reference, was used for electrochemical measurements. All experiments were carried out at room temperature.

\section{Result and Discussion}

3.1. Characterization of $\mathrm{Fe}_{3} \mathrm{O}_{4}$. The XRD spectrum of the asprepared $\mathrm{Fe}_{3} \mathrm{O}_{4}$ particles is shown in Figure 1(a). In the $2 \theta$ range of $20-70^{\circ}$, the peak positions at corresponding $2 \theta$ value are indexed as (2 000$),\left(\begin{array}{lll}3 & 1 & 1\end{array}\right),\left(\begin{array}{lll}4 & 0 & 0\end{array}\right),\left(\begin{array}{lll}5 & 1 & 1\end{array}\right)$, and (4 $\left.4 \begin{array}{ll}4 & 0\end{array}\right)$, respectively [23]. It is demonstrated that no impurity peaks are detected and the high purity $\mathrm{Fe}_{3} \mathrm{O}_{4}$ spinel structure is synthesized. A particle diameter of about $12 \mathrm{~nm}$ was calculated according to Scherrer's formula from the peak widths. 


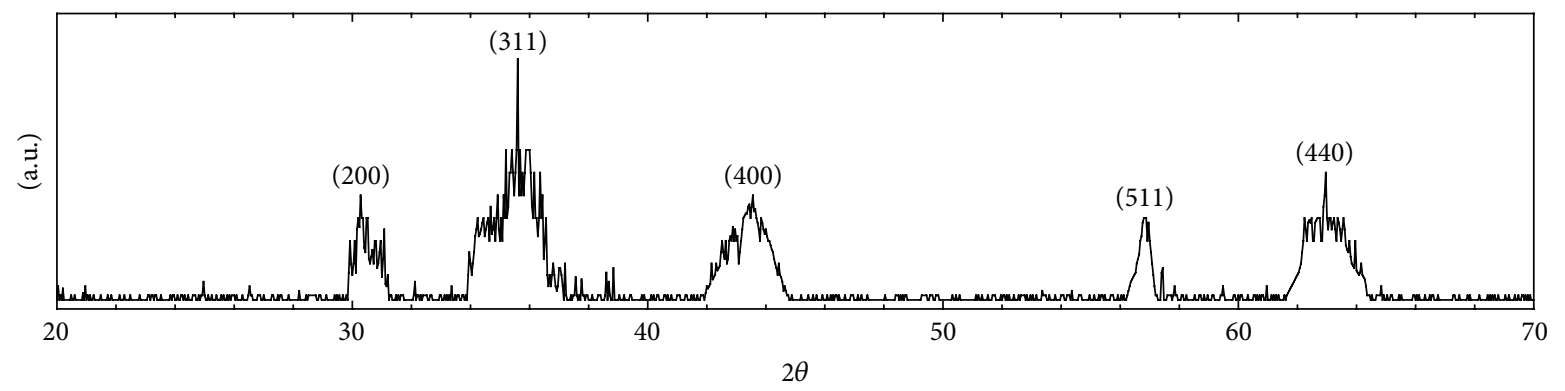

$-\mathrm{Fe}_{3} \mathrm{O}_{4} \mathrm{MNP}$

(a)

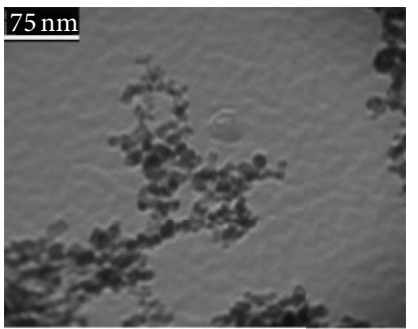

(b)

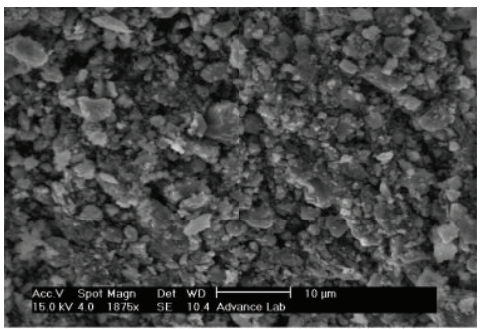

(c)

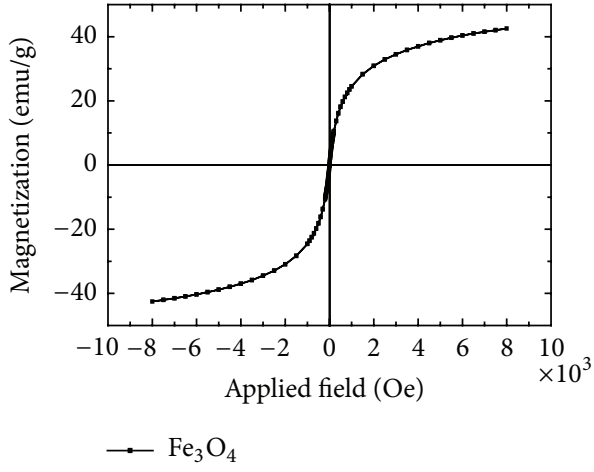

(d)

Figure 1: Typical (a) XRD, (b) TEM, (c) SEM image, and hysteresis loop pattern (d) of as-prepared magnetite nanoparticles (MNPs). The scale bar in TEM and SEM image is $75 \mathrm{~nm}$ and $10 \mu \mathrm{m}$, respectively.

The size and morphology of as-prepared $\mathrm{Fe}_{3} \mathrm{O}_{4}$ particles were further examined by TEM and SEM, and magnetization was studied by VSM (Figures 1(b), 1(c), and 1(d), resp.). Figure 1(b) shows a typical TEM image of as-prepared $\mathrm{Fe}_{3} \mathrm{O}_{4}$ nanoparticles. As displayed, the particles exhibited spherical morphology but with small tendency to agglomeration. In general, magnetite nanoparticles that synthesized through the coprecipitation are usually agglomerate, that to achieve stable colloids and avoid agglomeration, the surface of magnetite nanoparticles precipitate can be modified by desired organic or inorganic modifiers. Consequently, a big agglomeration is predicted in the bulk $\mathrm{Fe}_{3} \mathrm{O}_{4}$ nanoparticles as displayed in the SEM image (Figure 1(b)). As can be seen from the SEM image, morphology of bulk $\mathrm{Fe}_{3} \mathrm{O}_{4}$ particles is irregular but their distribution is uniform. However, from TEM image, the average size of dispersed $\mathrm{Fe}_{3} \mathrm{O}_{4}$ MNPs was estimated about $9 \mathrm{~nm}$. The specific surface area of $\mathrm{Fe}_{3} \mathrm{O}_{4}$ nanoparticles was $145 \mathrm{~m}^{2} \mathrm{~g}^{-1}$, which support nanosize of prepared $\mathrm{Fe}_{3} \mathrm{O}_{4}$ particles. The strong peaks for $\mathrm{Fe}$ and $\mathrm{O}$ were observed in the EDXA spectrum with atomic ratio of $1: 1.3$, which matches well with magnetite. The VSM magnetization of $\mathrm{Fe}_{3} \mathrm{O}_{4}$ nanoparticles at room temperature was recorded (Figure $1(\mathrm{~d})$ ). The results proved that the magnetic nanoparticles exhibited typical superparamagnetic behavior, characterized with strong magnetic susceptibility and no hysteresis, remanence, and coercivity (see Table SM1 in Supplementary Materials, containing complementary information of VSM and voltammetry, available online at http://dx.doi.org/10.1155/2013/803672). These results verified the successful synthesize of $\mathrm{Fe}_{3} \mathrm{O}_{4}$ magnetic nanoparticles and superparamagnetic behavior of them.

\subsection{Electrochemical Characterization of the MCPE/MNP} Electrode. Cyclic voltammetry can provide information on changes of electrode surfaces during modification processes. Figure 2(a) presents the cyclic voltammograms for (A) the MCPE and (B) the MCPE/MNP electrodes in $0.1 \mathrm{M}$ $\mathrm{NaClO}_{4}$ containing $0.5 \mathrm{mM}\left[\mathrm{Fe}(\mathrm{CN})_{6}\right]^{3-/ 4-}$ as a redox probe. An increase in faradaic current was observed for the MCPE/MNP electrode (Figure 2(a), curve (B)). The peak current of $\left[\mathrm{Fe}(\mathrm{CN})_{6}\right]^{3-/ 4-}$ at the MCPE/MNP electrode increased linearly with the square root of the scan rate over the range of 50-500 $\mathrm{mV} \mathrm{s}^{-1}$ (Figure 2(b)); suggesting that the overall oxidation reduction of $\left[\mathrm{Fe}(\mathrm{CN})_{6}\right]^{3-/ 4-}$ at the modified electrode is controlled by the diffusion of $\left[\mathrm{Fe}(\mathrm{CN})_{6}\right]^{3-/ 4-}$ in solution. On the basis of this result, a surface area of $0.26 \mathrm{~cm}^{2}$ was calculated for the prepared MCPE/MNP electrode, using the Randle Sevcik equation [35]. By comparison of the surface area of the MCPE/MNP $\left(0.26 \mathrm{~cm}^{2}\right)$ with the MCPE $\left(0.12 \mathrm{~cm}^{2}\right)$, it is indicated that the increased faradaic current of the MCPE/MNP may be due to presence of nanometer sized $\mathrm{Fe}_{3} \mathrm{O}_{4}$ particles on the electrode surface (compare curves (A) and (B) in Figure 2(a)).

Determination of the surface charge or surface $\mathrm{p} K_{a}$ has important significance in both theory and practice [36]. 


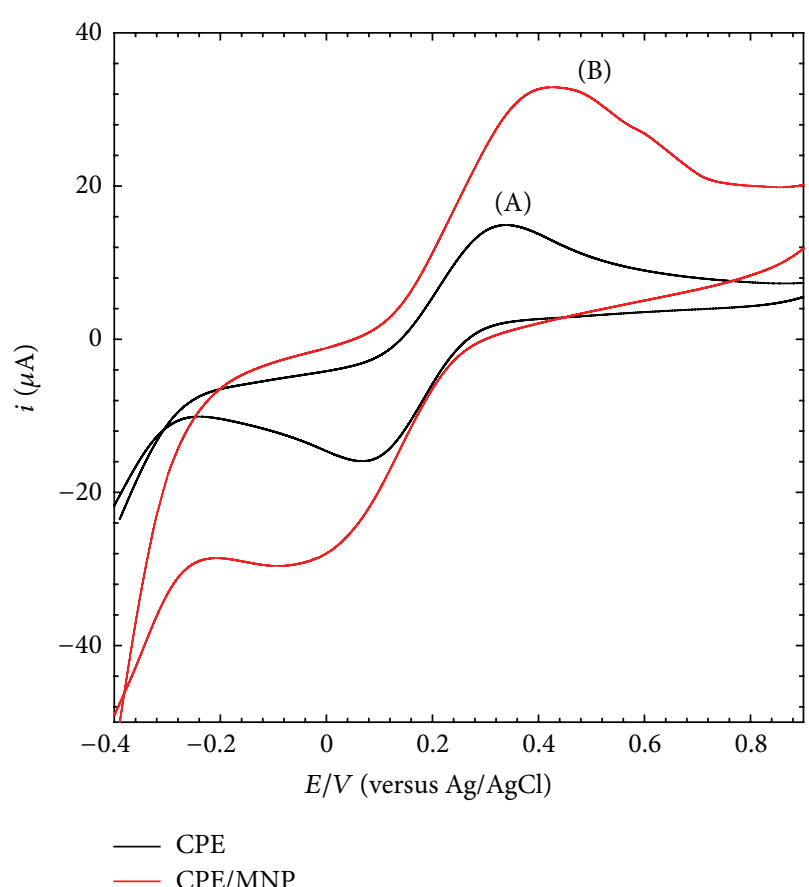

(a)

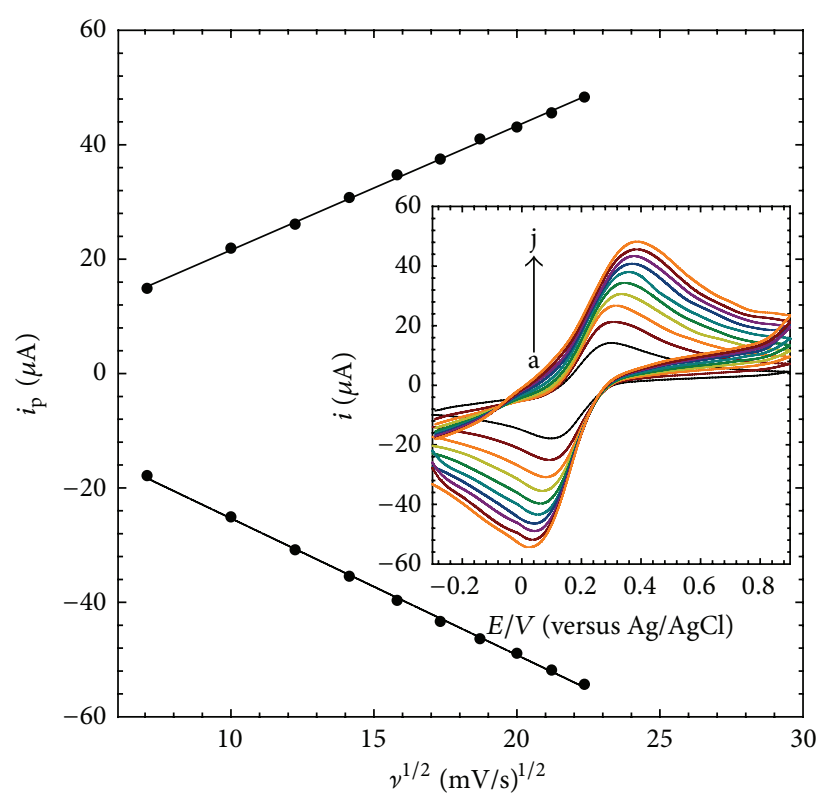

(b)

Figure 2: (a) The cyclic voltammograms of (A) the MCPE and (B) the MCPE/MNP in a solution of $0.1 \mathrm{M} \mathrm{NaClO}_{4}$ containing $0.5 \mathrm{mM}$ $\left[\mathrm{Fe}(\mathrm{CN})_{6}\right]^{3-/ 4-}$, scan rate $100 \mathrm{mV} \mathrm{s}^{-1}$. (b) Linear relationship of $i_{\mathrm{p}}$ and square root of scan rate $\left(v^{1 / 2}\right)$ at the MCPE/MNP. Inset is the cyclic voltammograms of the MCPE/MNP in a solution of $0.1 \mathrm{M} \mathrm{NaClO}_{4}$ containing $0.5 \mathrm{mM}\left[\mathrm{Fe}(\mathrm{CN})_{6}\right]^{3-/ 4-}$ with different scan rates $((\mathrm{a})-(\mathrm{j}): 50,100$, $150,200,250,300,350,400,450$, and $500 \mathrm{mV} \mathrm{s}^{-1}$ ).

In this propose, several methods have been previously reviewed and adopted [37]. Amongst them, the electrochemical methods have been found to be the simplest and most convenient approaches for the determination of surface charge and surface $\mathrm{p} K_{a}$. Accordingly, the surface charge or surface $\mathrm{p} K_{a}$ of the MCPE/MNP electrode was evaluated in a straightforward manner in this study using Faradaic current titration.

We estimated the surface $\mathrm{p} K_{a}$ of the modified electrode using CV measurements, that is, faradaic current titration. The surface $\mathrm{p} K_{a}$ of the MCPE/MNP electrode was estimated by recording cyclic voltammograms over a wide range of $\mathrm{pH}$ values (Figure 3(a)), and then monitoring $i_{\mathrm{p}}$ as a function of $\mathrm{pH}$. A value of $6.3 \pm 0.1$ was obtained from the midpoint of the titration curve for the MCPE/MNP electrode (Figure $3(\mathrm{~b})$ ). This value is comparable with the $\mathrm{pH}$ value of 6.5 reported in the literature for the zero potential charge (ZPC) of $\mathrm{Fe}_{3} \mathrm{O}_{4}$ [38]. It means that in the $\mathrm{pH}$ region of above 6.5 , the surface is negatively charged. Surface $\mathrm{p} K_{a}$ is an essential quantity to estimate the charge-state of the surfaces and to explain the behavior of the modified electrodes towards charged probes or biological molecules like DA and AA.

3.3. Interaction of $\mathrm{DA}$ and $\mathrm{AA}$ with $\mathrm{Fe}_{3} \mathrm{O}_{4} \mathrm{MNP}$. The comparison of the cyclic voltammograms for the oxidation-reduction of $\mathrm{AA}, \mathrm{DA}$ and a mixture of $\mathrm{AA}$ and $\mathrm{DA}$ at the MCPE and the MCPE/MNP electrodes showed that the presence of MNP on the MCPE electrode decreased the peak current and increased over potential for AA oxidation, increased the peak current and over potential for DA oxidation, and did not lead to peak separation in the oxidation potential of AA and DA (Supplementary Materials, Figure SM1 and Table SM2). Additionally, comparison of the SWVs for AA, DA, and a mixture of AA and DA showed no separation between their oxidation potentials. However, an interesting behavior was observed after incubation of the MCPE/MNP electrode in $\mathrm{AA}$ and DA. Figure 4 presents the electrochemical responses of the MCPE/MNP electrode in PBS ( $\mathrm{pH}$ 7.0) after preconcentration of the MCPE/MNP electrode in PBS ( $\mathrm{pH} 7.0$ ) containing $1.0 \times 10^{-3} \mathrm{M} \mathrm{AA}$ (curve (B)) or $5.0 \times 10^{-5} \mathrm{M} \mathrm{DA}$ (curve (C)) for $30 \mathrm{~min}$. A sharp wave with a high peak current due to DA oxidation was observed at the MCPE/MNP electrode; however, the same wave was not observed for AA. This behavior is due to the adsorption of DA to $\mathrm{Fe}_{3} \mathrm{O}_{4} \mathrm{NPs}$ and allows us to present a selective sensor for DA based on strategy (ii).

Further studies were performed to verify the adsorption between DA and MNPs. The peak current for the oxidation of pre-concentrated DA on the MCPE/MNP electrode increased linearly with the scan rate over the range of 50$400 \mathrm{mV} \mathrm{s}^{-1}$ (Figure 5). This suggests that the overall oxidation/reduction of DA at the modified electrode is controlled by an adsorption phenomenon.

Our literature survey reviled some reports on the attachment of DA as a robust anchor to immobilize functional molecules on MNPs by sonication of the DA and MNPs during $30 \mathrm{~min}$ [27-31]. Thus, the adsorption of DA on MNPs without 


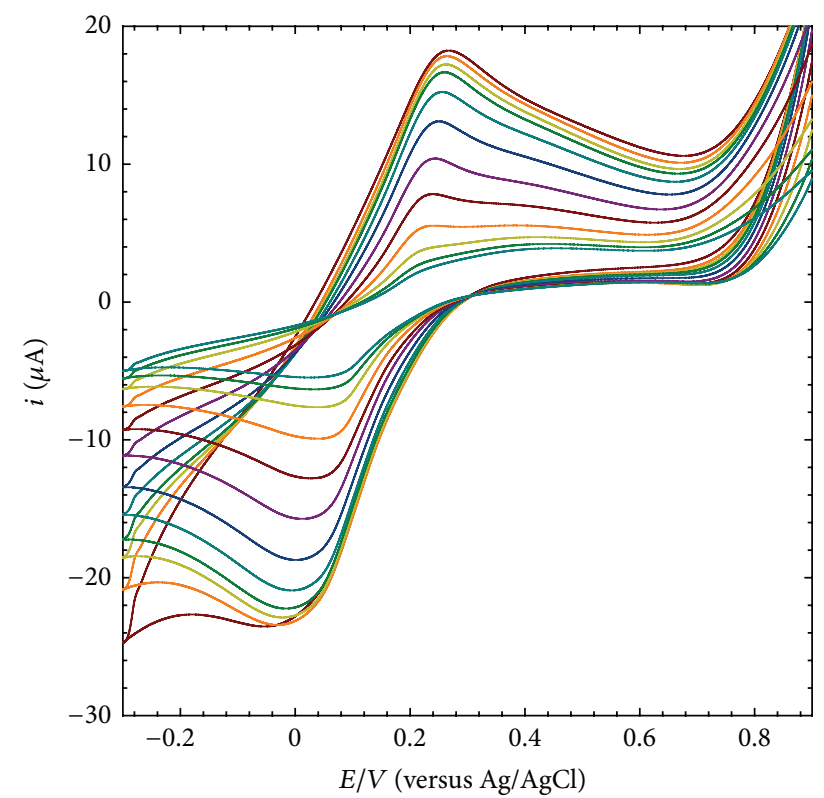

(a)

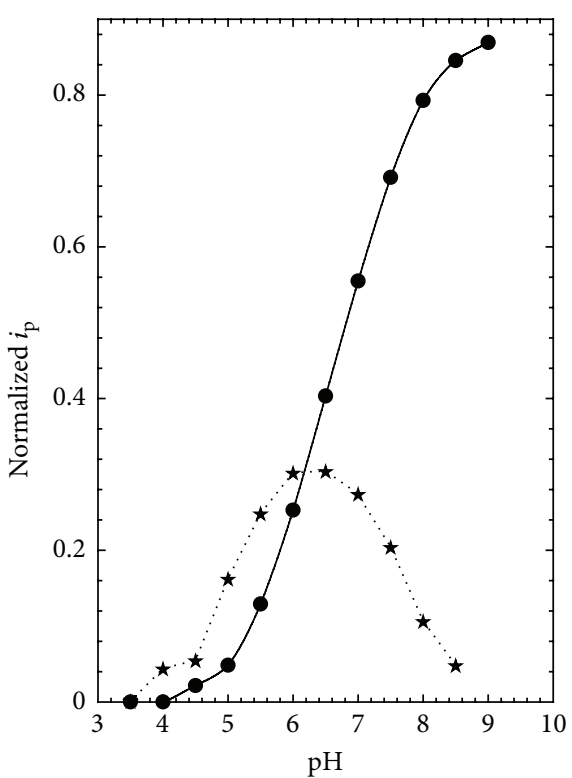

(b)

Figure 3: (a) The cyclic voltammograms obtained at the MCPE/MNP in $0.1 \mathrm{M}$ PBS containing $0.1 \mathrm{M} \mathrm{NaClO}_{4}$ in the presence of $0.5 \mathrm{mM}$ $\left[\mathrm{Fe}(\mathrm{CN})_{6}\right]^{3-/ 4-}$ at different $\mathrm{pH}$. Outer to inner; $\mathrm{pH}$ 2.5, 3.0, 4.1, 4.6, 5.0, 5.5, 6.0, 6.5, 7.0, 7.5, 8.0, 8.5, 9.0, and 9.5. (b) Faradaic current titration curve for the MCPE/MNP (solid line) and its first derivative (dotted line), normalized $i_{\mathrm{p}}$ is $\left(i_{\mathrm{p}}(\max )-i_{\mathrm{p}}\right) / i_{\mathrm{p}}(\max )$.

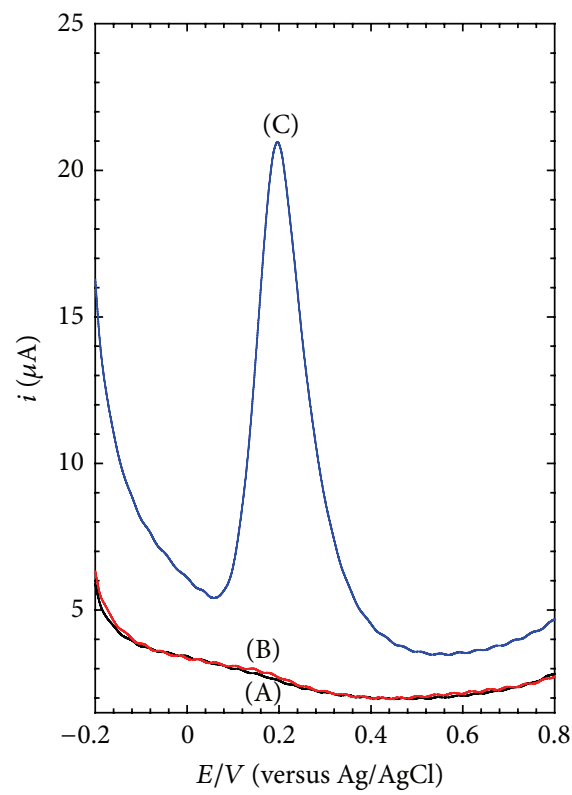

FIGURE 4: The square wave voltammograms obtained on the MCPE/ MNP in PBS, DA free, $\mathrm{pH} 7.0$, and $0.1 \mathrm{M} \mathrm{NaClO}_{4}$ after 30 min preconcentration in PBS ( $\mathrm{pH} 7.0$ ) containing (B) $1.0 \times 10^{-3} \mathrm{M} \mathrm{AA},(\mathrm{C})$ $5.0 \times 10^{-5} \mathrm{M}$ DA. Curve (A) was obtained from blank solution.

sonication was compared to the reported sonication route. Therefore, $200 \mathrm{~mL}$ of $0.1 \mathrm{M}$ PBS $(\mathrm{pH} 7.0)$ containing $1.0 \times$ $10^{-3} \mathrm{M}$ DA was (a) stirred with $200 \mathrm{mg}$ MNPs for $30 \mathrm{~min}$ to form MNP/DA (stirred) or (b) sonicated with $200 \mathrm{mg}$ MNPs for $30 \mathrm{~min}$ to form MNP/DA (sonicated). The resulting

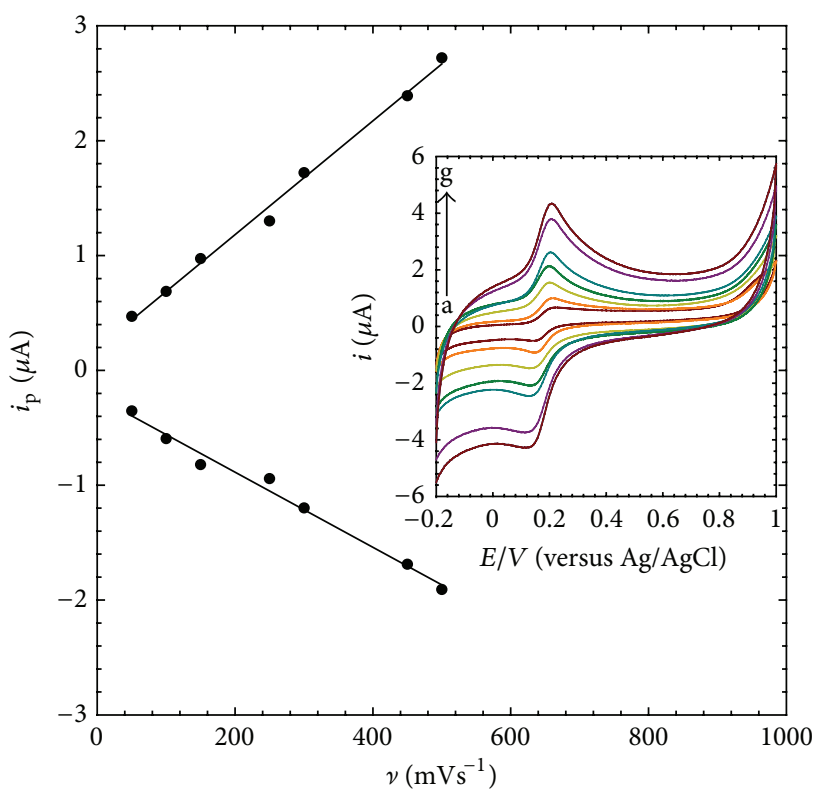

FIGURE 5: Linear relationship of $i_{\mathrm{p}}$ of DA oxidation/reduction and scan rate $(\nu)$ at the MCPE/MNP. Inset is the cyclic voltammograms of the MCPE/MNP in PBS, DA free, $\mathrm{pH} 7.0$, and $0.1 \mathrm{M} \mathrm{NaClO}_{4}$ after 30 min pre-concentration in PBS ( $\mathrm{pH} 7.0$ ) containing $1 \mathrm{mM} \mathrm{DA}$ with different scan rates ((a)-(g): 50, 100, 150, 250, 300, 450, and $500 \mathrm{mV} \mathrm{s}^{-1}$ ).

MNP/DA was removed, washed several times, and then compared via FTIR spectroscopy (Figure 6).

Comparison of the FTIR spectrums of DA-coated particles and naked MNP (Figure 6(a)) demonstrated the weak, 


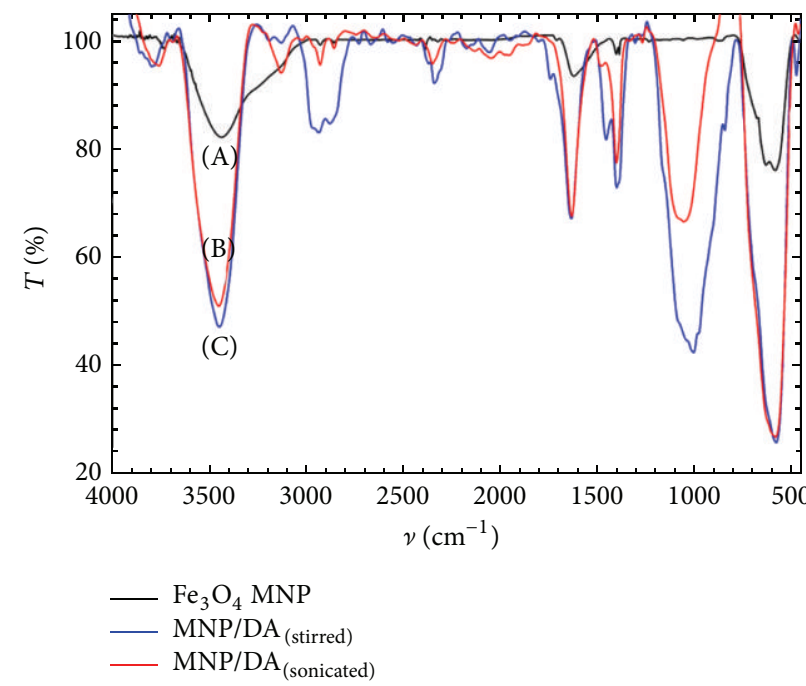

(a)

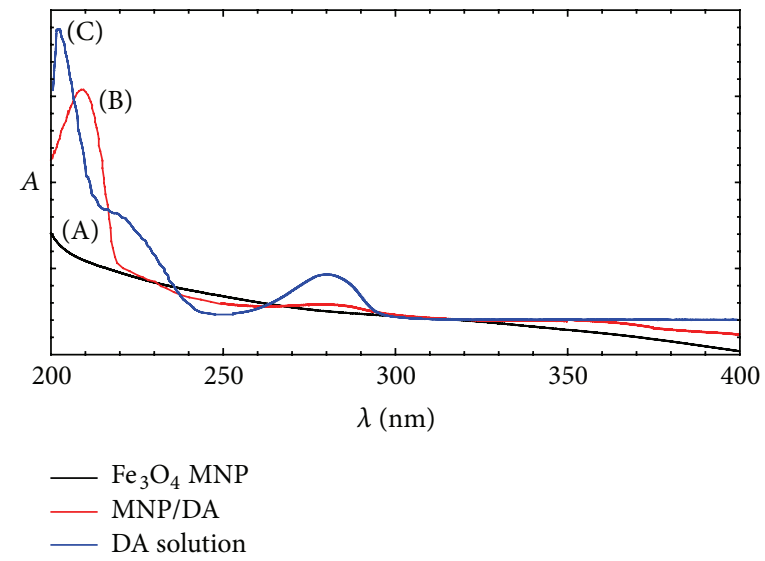

(b)

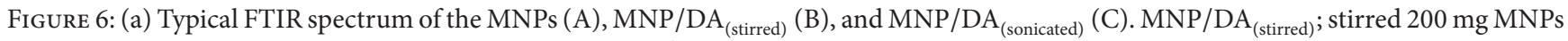
for $30 \mathrm{~min}$ in $200 \mathrm{~mL} \mathrm{PBS}, \mathrm{pH}=7.0$, containing $1.0 \times 10^{-3} \mathrm{M} \mathrm{DA}$. MNP/DA (sonicated); sonicated $200 \mathrm{mg} \mathrm{MNPs}$ for $30 \mathrm{~min}$ in $200 \mathrm{~mL} \mathrm{PBS}$, $\mathrm{pH}=7.0$, containing $1.0 \times 10^{-3} \mathrm{M}$ of DA. (b) UV-Vis spectrums of $\mathrm{Fe}_{3} \mathrm{O}_{4} \mathrm{MNPs}(\mathrm{A}), \mathrm{Fe}_{3} \mathrm{O}_{4} / \mathrm{DA}$ (B) and DA molecule (C).

wide absorption peaks at approximately $1090-1700 \mathrm{~cm}^{-1}$ in spectra (b) and (c) which could be attributed to vibration of the $\mathrm{C}-\mathrm{O}$ bond in $\mathrm{Fe}_{3} \mathrm{O}_{4} / \mathrm{DA}$. This feature was not observed in pure $\mathrm{Fe}_{3} \mathrm{O}_{4}$ MNPs (spectrum A). The absorption peak at $580 \mathrm{~cm}^{-1}$ was attributed to $\mathrm{Fe}-\mathrm{O}$ vibration in unmodified $\mathrm{Fe}_{3} \mathrm{O}_{4} \mathrm{MNP}$ and modified MNP in both route. However, the absorption peaks of MNP/DA (stirred or sonicated) were slightly wider than pure $\mathrm{Fe}_{3} \mathrm{O}_{4}$. It demonstrates that the vibration of the $\mathrm{Fe}-\mathrm{O}$ bond was altered in DA-modified $\mathrm{Fe}_{3} \mathrm{O}_{4}$, and indicates that the DA bonded to the surface of $\mathrm{Fe}_{3} \mathrm{O}_{4}$ MNPs via a $\mathrm{Fe}-\mathrm{O}-\mathrm{C}$ bond in both route. Figure 6(b) shows the UV-Vis spectrums of $\mathrm{Fe}_{3} \mathrm{O}_{4}$ MNPs (A), $\mathrm{Fe}_{3} \mathrm{O}_{4} / \mathrm{DA}(\mathrm{B})$, and DA molecule $(\mathrm{C})$. No absorption peaks were observed for the bare $\mathrm{Fe}_{3} \mathrm{O}_{4}$ (curve (A)). When DA was attached onto $\mathrm{Fe}_{3} \mathrm{O}_{4}$, a sharp absorption peak and another relatively broad peak were observed at 210 and $285 \mathrm{~nm}$, respectively (curve (B)). Compared to the spectra of pure DA (curve (C)), the deviation of the DA absorption wavelength could be ascribed to the interaction of $\mathrm{Fe}_{3} \mathrm{O}_{4}$ with DA molecules. The same results also are recently reported by $\mathrm{Li}$ et al. [39]. The obtained results demonstrate the successful attachment of DA onto the $\mathrm{Fe}_{3} \mathrm{O}_{4}$ MNPs.

Mechanism of selective adsorption of DA onto $\mathrm{Fe}_{3} \mathrm{O}_{4}$ MNPs surface can explicate by recent reports of Chen et al. [40]. They report that DA has ability to convert the coordinatively unsaturated iron surface sites back into a bulk-like lattice structure with an octahedral geometry for the oxygencoordinated iron centers, resulting in tight binding of DA to iron oxide, in compared to AA without diol on benzene ring, which caused to selectivity of the MCPE/MNPs toward DA.

\subsection{Optimization of the Adsorption Condition}

3.4.1. $p H$. DA ( $\left.\mathrm{p} K_{a}=8.9\right)$ exhibits a different charge depending on its $\mathrm{pH}[1]$, and as shown in this work MNP (surface $\mathrm{p} K_{a}$ of $\left.6.3 \pm 0.1\right)$ also, the interaction of MNPs with DA is influenced by the $\mathrm{pH}$ of the solution. Therefore, studying the $\mathrm{pH}$ effect on their interaction was a critical step in the current work. The $\mathrm{pH}$ effect was investigated in a $0.1 \mathrm{M}$ PBS containing $5.0 \times 10^{-5} \mathrm{M}$ of DA for $30 \mathrm{~min}$ pre-concentration time. Optimal conditions for pre-concentration and stripping steps were achieved around a pH of 7.0 (Figure 7(a)).

3.4.2. Pre-Concentration Time. The dependence of the anodic stripping peak current on the pre-concentration time at the MCPE/MNP electrodes was also studied. The MCPE/MNP electrodes were immersed in $0.1 \mathrm{M}$ PBS at $\mathrm{pH}=7.0$, containing $5.0 \times 10^{-5} \mathrm{M}$ of DA stirred solution for different time periods. The peak current was increased as a function of preconcentration time and the asymptotic value was reached within 20 min (Figure 7(b)).

3.4.3. Amount of MNP. The MCPE/MNP electrode response to adsorbed DAs was dependent on the amount of MNPs that were casted on the MCPE. Therefore, different amounts of MNPs (different $\mu \mathrm{L}$ of the homogenized $10 \mathrm{mg} \mathrm{mL}^{-1}$ MNPs suspension) were casted on the MCPE and its SWV response in PBS ( $\mathrm{pH}=7.0)$, DA free, after pre-concentration in $0.1 \mathrm{M}$ $\mathrm{PBS}$ at $\mathrm{pH}=7.0$, containing $5.0 \times 10^{-5} \mathrm{M}$ of DA for $20 \mathrm{~min}$, was recorded. As evident from Figure 7(c), higher response was observed for $6 \mu \mathrm{L}(60 \mu \mathrm{g})$ of MNPs suspension.

3.5. Optimization of Instrumental Parameters. The peak current of square wave voltammograms is also dependent on instrumental parameters. The instrumental parameters are interrelated and can be optimized by monitoring of the peak current as a function of studying parameter values, while other parameters are fixed. After a careful examination, the setting of pulse height $(10 \mathrm{mV})$, square wave amplitude 


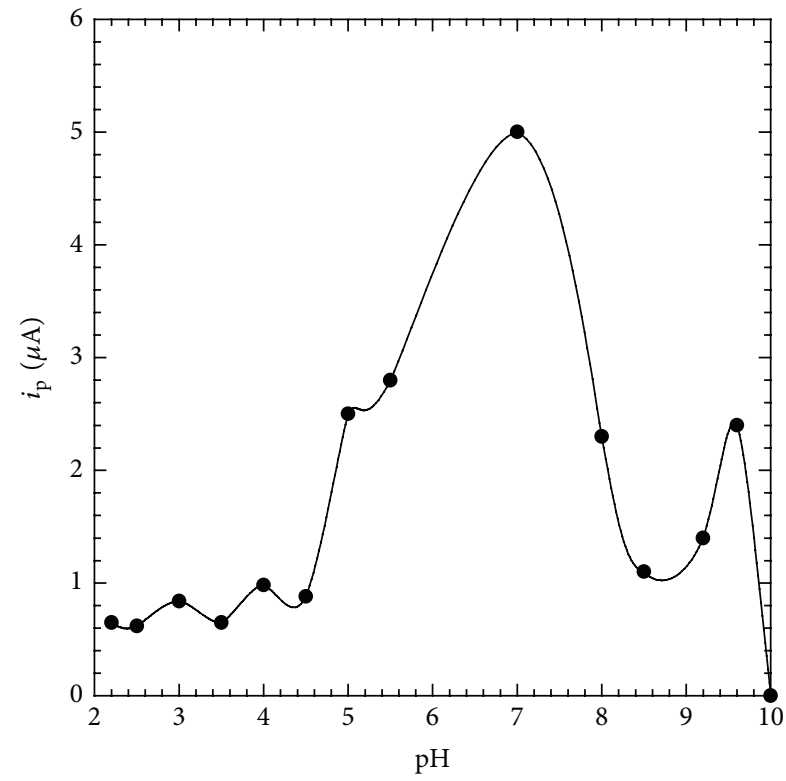

(a)

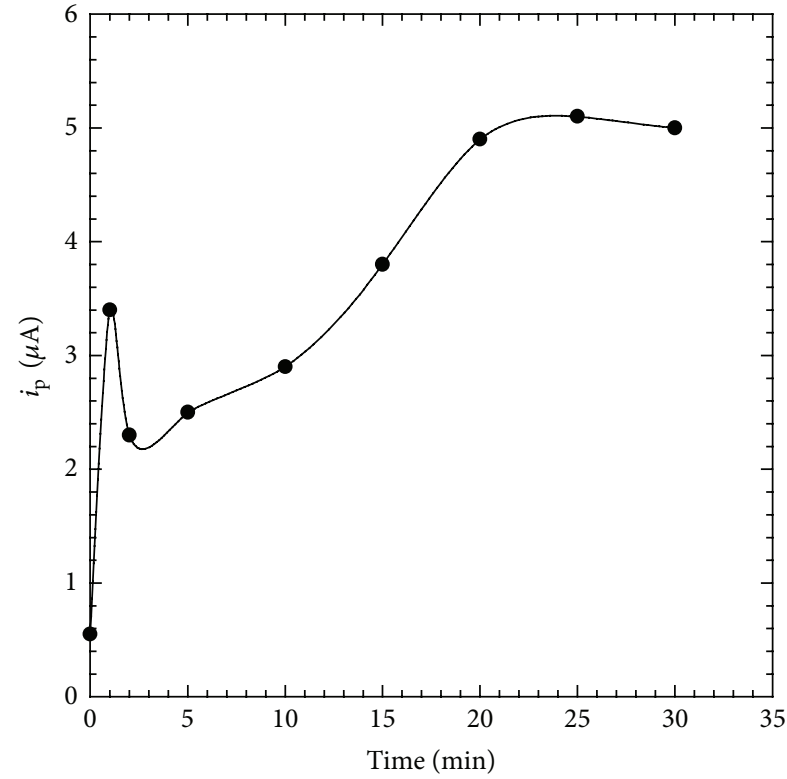

(b)

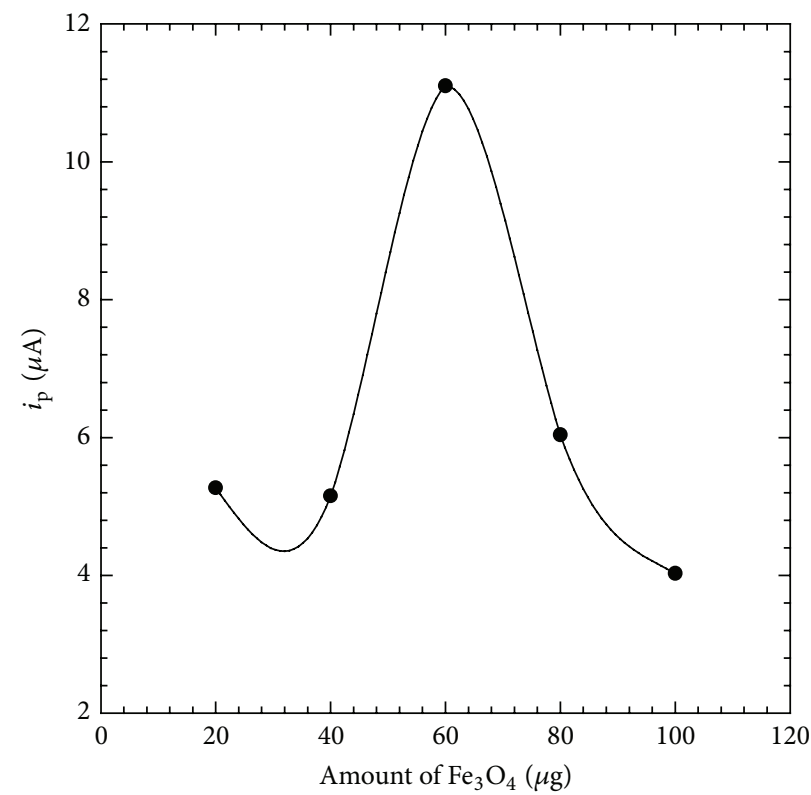

(c)

Figure 7: Response of the MCPE/MNP as a function of (a) pH, (b) pre-concentration time, and (c) amount of MNPs. Pre-concentration conditions: PBS (pH 7.0) containing 5.0 $\times 10^{-5} \mathrm{M} \mathrm{DA}$ at the open-circuit potential. Measurement conditions, SWV in PBS, DA free, pH 7.0, and $0.1 \mathrm{M} \mathrm{NaClO}_{4}$.

$(50 \mathrm{mV})$, and square wave frequency $(40 \mathrm{~Hz})$ were found as optimized values for instrumental parameters.

3.6. Calibration and Detection Limit. The calibration curve (Figure 8, inset) was obtained under optimized conditions by systematically increasing the concentration of DA from $5.0 \times$ $10^{-6}$ to $1.0 \times 10^{-3} \mathrm{M}$ in pre-concentration solution containing $1.0 \times 10^{-3} \mathrm{M}$ AA (PBS, $\mathrm{pH}=7.0$ ) and by monitoring the response of the MCPE/MNP electrode in determination solution by $\operatorname{SWV}\left\{\left(i_{\mathrm{p}}-i_{\mathrm{pb}}\right) / \mu \mathrm{A}=100.1( \pm 1.123) / \mu \mathrm{A}+\right.$ $\left.18.62( \pm 0.271) \log ([\mathrm{DA}] / \mathrm{M}), r^{2}=0.999\right\}$. The detection limit of this electrode, calculated from the standard deviation of the background (signal equals $3 \delta$ of the background noise), is $7.6 \times 10^{-7} \mathrm{M} \mathrm{DA}$, with a relative standard deviation of $4.6 \%(n=5)$ for $5.0 \times 10^{-5} \mathrm{M} \mathrm{DA}$. The reproducibility of the MCPE/MNP electrode was evaluated by RSD, $n=5$, of the DA with different electrodes. The RSD of $5.0 \%$ was obtained at $5.0 \times 10^{-5} \mathrm{M}$ DA. These results indicated the 


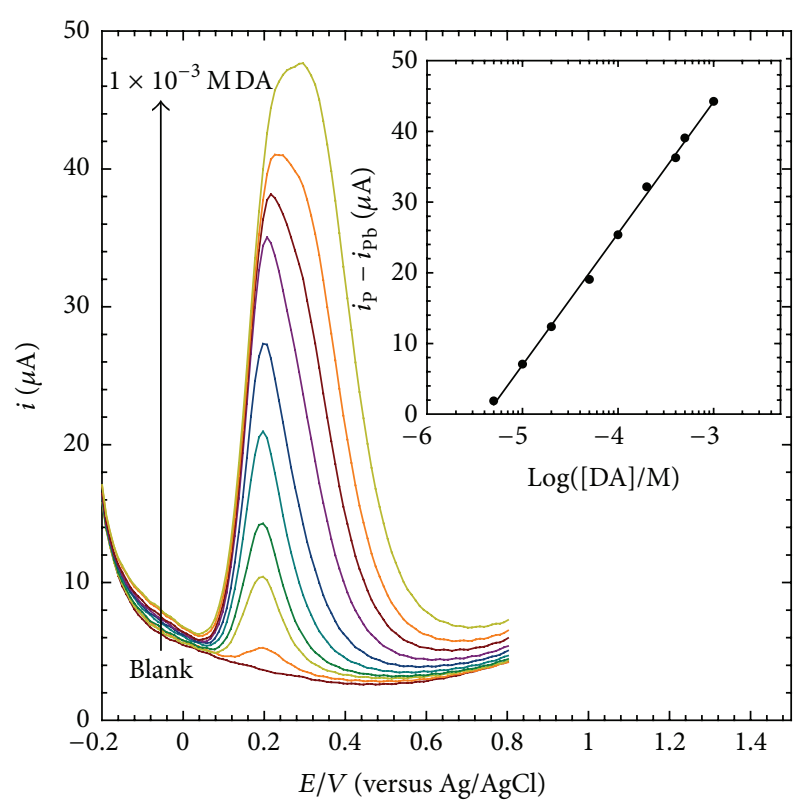

FIGURE 8: The square wave voltammograms obtained on the MCPE/ MNP in PBS, DA free, $\mathrm{pH} 7.0$, and $0.1 \mathrm{M} \mathrm{NaClO}_{4}$ after 20 min preconcentration in PBS ( $\mathrm{pH} 7.0$ ) containing $1.0 \times 10^{-3} \mathrm{M} \mathrm{AA}$ and different concentrations of DA; bottom to top: $0.0,5.0 \times 10^{-6}, 1.0 \times$ $10^{-5}, 2.0 \times 10^{-5}, 5.0 \times 10^{-5}, 1.0 \times 10^{-4}, 2.0 \times 10^{-4}, 4.0 \times 10^{-4}, 5.0 \times 10^{-4}$, and $1.0 \times 10^{-3} \mathrm{M}$ DA. SWV conditions were as; pulse height $(10 \mathrm{mV})$, square wave amplitude $(50 \mathrm{mV})$, and square wave frequency $(40 \mathrm{~Hz})$. Inset is calibration curve $\left\{\left(i_{\mathrm{p}}-i_{\mathrm{pb}}\right) / \mu \mathrm{A}=100.1( \pm 1.123) / \mu \mathrm{A}+18.62\right.$ $\left.( \pm 0.271) \log ([\mathrm{DA}] / \mathrm{M}), r^{2}=0.999\right\}$ obtained from variation of the SWV anodic peak current as a function of DA concentration. $\left(i_{\mathrm{pb}}\right.$; anodic peak current of blank).

good and acceptable reproducibility and repeatability of the MCPE/MNP electrode.

The interday and intraday stability of the MCPE/MNP electrode was assessed by determination of $5.0 \times 10^{-5} \mathrm{M} \mathrm{DA}$. The inter-day stability of our proposed method was detected by using a prepared MCPE/MNP electrode with three different days in a week. The RSD of inter-day stability was obtained as $4.8 \%$. Similarly, the intra-day stability was evaluated from the response to the same prepared MCPE/MNP electrode and detected three times every day. The RSD of intra-day was obtained $5.7 \%, 6.1 \%$, and $5.8 \%$, respectively. Thus, the interday and intra-day stabilities of the modified electrode were acceptable.

The interference of a few common interferes was investigated in the presence of $1.0 \times 10^{-3} \mathrm{M} \mathrm{DA} . \mathrm{Na}^{+}, \mathrm{Ca}^{2+}, \mathrm{Mg}^{2+}$, glucose and sucrose in 500-fold, and AA in 10-fold of the DA concentration did not change the signal of SWV. However, based on mentioned interaction mechanism between $\mathrm{Fe}_{3} \mathrm{O}_{4}$ MNPs and diol on benzene ring of DA molecule, there is a possibility of the same behavior for other catechols compounds like norepinephrine, methyldopa, and epinephrine. We investigated interaction of epinephrine as one of the important interferes of DA, with MCPE/MNPs electrode, and the same adsorption behavior was observed for it, but with totally different oxidation potential $(0.4 \mathrm{~V})$ in comparison to
DA $(0.2 \mathrm{~V})$. This result showed that proposed modified electrode may be suitable for catechol derivative distinguishing. However, the aim of this work was study of the selectivity of $\mathrm{Fe}_{3} \mathrm{O}_{4}$ MNPs toward DA and AA, and its interaction with other catechols not intended here.

On the other hand, a literature survey reviled that there is a similar report on application of $\mathrm{Fe}_{3} \mathrm{O}_{4} \mathrm{MNP}$ in voltammetric sensing of DA by using a gold electrode [26]. But there are distinct differences between our work and previous papers. In the previous reports, the dopamine determination was done based on the diffusion current of DA oxidation at the modified electrode, not based on pre-concentration of DA on top of the modified electrode (our method). The premier advantage of our work is high selectivity of our method to detection of dopamine against AA. Furthermore, our investigation showed if determination was done based on diffusion current, a fouling effect was observed due to oxidation products on the electrode surface (Supplementary Materials, Figure SM2.). Finally, the observed results are not only important in view of analytical chemistry but also are critical in view point of MNP modification. Because our results showed that there is a simple approach for amination of MNP via attachment of DA to $\mathrm{MNP}\left(\mathrm{Fe}_{3} \mathrm{O}_{4}\right)$.

3.7. Analytical Performance for Determination of DA in Pharmaceutical Sample. The proposed sensor was tested for determination of DA in dopamine hydrochloride injection samples. Pharmaceutical samples were prepared and adjusted to $5.0 \times 10^{-6} \mathrm{M} \mathrm{DA}$, in $0.1 \mathrm{M}$ PBS, $\mathrm{pH} 7.0$, by dilution of DOPADIC ampoule contents $\left(5 \mathrm{~mL}\right.$ of $200 \mathrm{mg} \mathrm{mL}^{-1} \mathrm{DA}$ hydrochloride injection solution). The standard additions of DA were done by addition of different concentrations of DA to this sample. After pre-concentration of the MCPE/MNP electrode in these solutions, the square wave voltammograms were recorded (displayed in Figure 9, inset). The anodic peak currents were extracted and plotted versus DA concentration. A linear relation $\left\{i_{\mathrm{p}} / \mu \mathrm{A}=102.2( \pm 6.543) / \mu \mathrm{A}+\right.$ $\left.19.39( \pm 1.560) \log ([\mathrm{DA}] / \mathrm{M}), r^{2}=0.997\right\}$ was found from variations of $i_{\mathrm{p}}$ versus DA concentrations (Figure 9). Obtained result $\left(5.3 \times 10^{-6} \mathrm{M} \mathrm{DA}\right)$ was in good agreement with the value of dopamine hydrochloride in diluted sample, $\mathrm{RSD} \cong 7.2 \%$.

\section{Conclusion}

Here, $\mathrm{Fe}_{3} \mathrm{O}_{4}$ superparamagnetic iron oxide nanoparticles were successfully synthesized via coprecipitation method and characterized. Then a simple magnetic carbon paste electrode was modified with the magnetic nanoparticles, MCPE/MNP, and characterized by electrochemical methods in the presence of $\left[\mathrm{Fe}(\mathrm{CN})_{6}\right]^{3-/ 4-}$ as a redox probe. Surface $\mathrm{p} K_{a}$ of the $\mathrm{MCPE} / \mathrm{MNP}$ was evaluated as $6.3 \pm 0.1$ by using Faradaic current titration method. Interaction of the MCPE/MNP with DA was investigated, and the results proved an adsorption behavior between $\mathrm{Fe}_{3} \mathrm{O}_{4}$ and DA. Based on this behavior, a calibration curve from $5.0 \times 10^{-6}$ to $1.0 \times 10^{-3} \mathrm{M} \mathrm{DA}$ with correlation coefficients of 0.999 and a detection limit of $7.6 \times 10^{-7} \mathrm{M} \mathrm{DA}$ was constructed by using the MCPE/MNP. The MCPE/MNP showed good selectivity, reproducibility, 


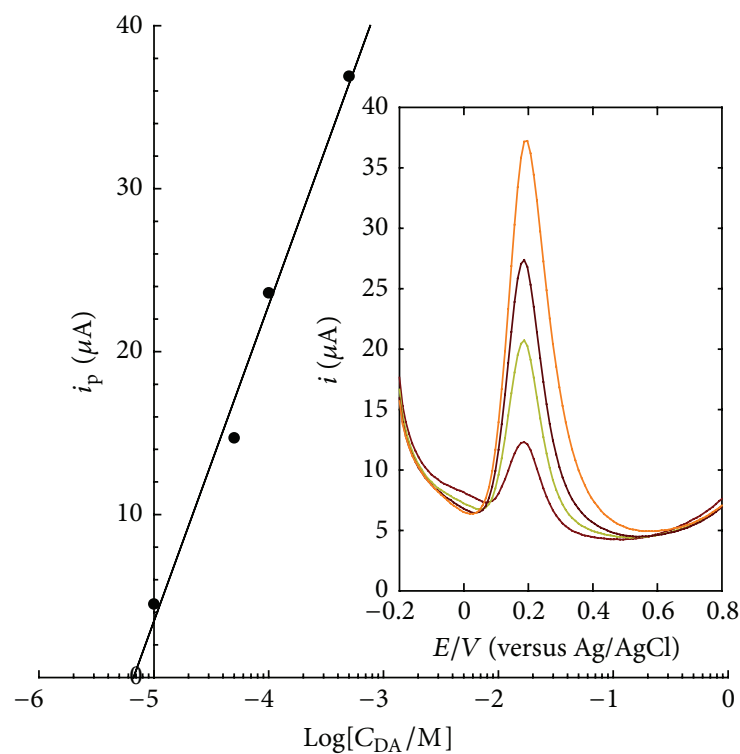

FIgURE 9: Calibration curve $\left\{i_{\mathrm{p}} / \mu \mathrm{A}=102.2( \pm 6.543) / \mu \mathrm{A}+19.39\right.$ $\left.( \pm 1.560) \log ([\mathrm{DA}] / \mathrm{M}), r^{2}=0.997\right\}$ obtained from variation of the SWV anodic peak current as a function of DA concentration in standard addition solutions. Inset shows square wave voltammograms obtained on the MCPE/MNP in $5.0 \times 10^{-6} \mathrm{M}$ DOPADIC solution prepared by standard addition method, inner to outer; $1.0 \times 10^{-5}$, $5.0 \times 10^{-5}, 1.0 \times 10^{-4}$, and $5.0 \times 10^{-4} \mathrm{M} \mathrm{DA}$. Conditions are the same as in Figure 8.

and stability for the detection of trace DA, especially in the presence of AA. Another challenge is that this modified MNP (MNP/DA), with amine end functional group, could be further modified by large molecular complexing agents for sensor and clinical application or radiolabeling; this work is in progress.

\section{Conflict of Interests}

The authors do not have any financial interest or any other conflict of interests with the commercial identities mentioned in this paper.

\section{Acknowledgment}

The authors gratefully acknowledge the NSTRI for providing facilities for this work.

\section{References}

[1] R. M. Wightman, L. J. May, and A. C. Michael, "Detection of dopamine dynamics in the brain," Analytical Chemistry, vol. 60, no. 13 , pp. 769-779, 1988.

[2] T. E. Smith, Textbook of Biochemistry with Clinical Correlations, Edited by T. M. Devlin, Wiley-Liss, New York, NY, USA, 1992.

[3] J. A. Stamford and J. B. Justice, "Peer reviewed: probing brain chemistry: voltammetry comes of age," Analytical Chemistry, vol. 6811, pp. 359A-363A, 1996.
[4] B. J. Venton, K. P. Troyer, and R. M. Wightman, "Response times of carbon fiber microelectrodes to dynamic changes in catecholamine concentration," Analytical Chemistry, vol. 74, no. 3, pp. 539-546, 2002.

[5] R. K. Shervedani, M. Bagherzadeh, and S. A. Mozaffari, "Determination of dopamine in the presence of high concentration of ascorbic acid by using gold cysteamine self-assembled monolayers as a nanosensor," Sensors and Actuators B, vol. 115, no. 2, pp. 614-621, 2006.

[6] R. K. Shervedani and M. Bagherzadeh, "Electrochemical characterization of in situ functionalized gold cysteamine selfassembled monolayer with 4 -formylphenylboronic acid for detection of dopamine," Electroanalysis, vol. 20, no. 5, pp. 550557, 2008.

[7] R. K. Shervedani, S. M. Siadat-Barzoki, and M. Bagherzadeh, "Electrochemical characterization of gold 6-amino-2-mercaptobenzothiazole self-assembled monolayer for dopamine detection in pharmaceutical samples," Electroanalysis, vol. 22, no. 9, pp. 969-977, 2010.

[8] A. Domenech, H. Garcia, M. T. Domenech-Carbo, and M. S. Galletero, "2,4,6-triphenylpyrylium ion encapsulated into zeolite $\mathrm{Y}$ as a selective electrode for the electrochemical determination of dopamine in the presence of ascorbic acid "' Analytical Chemistry, vol. 74, pp. 562-569, 2002.

[9] R. D. O'Neill, "Microvoltammetric techniques and sensors for monitoring neurochemical dynamics in vivo: a review," Analyst, vol. 119, pp. 767-779, 1994.

[10] P. Capella, M. B. Ghasemzadeh, K. Mitchell, and R. N. Adams, "Nafion-coated carbon fiber electrodes for neurochemical studies in brain tissue," Electroanalysis, vol. 2, no. 3, pp. 175-182, 1990.

[11] D. Lakshmi, A. Bossi, M. J. Whitcombe et al., "Electrochemical sensor for catechol and dopamine based on a catalytic molecularly imprinted polymer-conducting polymer hybrid recognition element," Analytical Chemistry, vol. 81, no. 9, pp. 35763584, 2009.

[12] X. Kan, Y. Zhao, Z. Geng, Z. Wang, and J.-J. Zhu, "Composites of multiwalled carbon nanotubes and molecularly imprinted polymers for dopamine recognition," Journal of Physical Chemistry C, vol. 112, no. 13, pp. 4849-4854, 2008.

[13] M. Wei, L. G. Sun, Z. Y. Xie et al., Advanced Functional Materials, vol. 18, p. 1608, 2008.

[14] M. C. Rodriguez, M. D. Rubianes, and G. A. Rivas, "Highly selective determination of dopamine in the presence of ascorbic acid and serotonin at glassy carbon electrodes modified with carbon nanotubes dispersed in polyethylenimine," Journal of Nanoscience and Nanotechnology, vol. 8, no. 11, pp. 6003-6009, 2008 .

[15] S. Hou, M. L. Kasner, S. Su, K. Patel, and R. Cuellari, "Highly sensitive and selective dopamine biosensor fabricated with silanized graphene," Journal of Physical Chemistry C, vol. 114, no. 35, pp. 14915-14921, 2010.

[16] M. Bagherzadeh and M. Heydari, "Electrochemical detection of dopamine based on pre-concentration by graphene nanosheets," Analyst, vol. 138, pp. 6044-6051, 2013.

[17] A. H. Lu, E. L. Salabas, and F. Schuth, "Magnetic nanoparticles: synthesis, application," Angewandte Chemie International Edition, vol. 46, no. 8, 2007.

[18] M. Faraji, Y. Yamini, and M. Rezaee, "Magnetic nanoparticles: synthesis, stabilization, functionalization, characterization, and applications," Journal of the Iranian Chemical Society, vol. 7, no. 1, pp. 1-37, 2010. 
[19] M. Lattuada and T. A. Hatton, "Functionalization of monodisperse magnetic nanoparticles," Langmuir, vol. 23, no. 4, pp. 2158-2168, 2007.

[20] S. Laurent, D. Forge, M. Port et al., "Magnetic iron oxide nanoparticles: synthesis, stabilization, vectorization, physicochemical characterizations, and biological applications," Chemical Reviews, vol. 108, no. 6, pp. 2064-2110, 2008.

[21] H. Qu, D. Caruntu, H. Liu, and C. J. O’Connor, "Water-dispersible iron oxide magnetic nanoparticles with versatile surface functionalities," Langmuir, vol. 27, no. 6, pp. 2271-2278, 2011.

[22] S. Sun, H. Zeng, D. B. Robinson et al., "Monodisperse $\mathrm{MFe}_{2} \mathrm{O}_{4}$ ( $\mathrm{M}=\mathrm{Fe}, \mathrm{Co}, \mathrm{Mn})$ nanoparticles," Journal of the American Chemical Society, vol. 126, no. 1, pp. 273-279, 2004.

[23] J. Gong and X. Lin, "Facilitated electron transfer of hemoglobin embedded in nanosized $\mathrm{Fe}_{3} \mathrm{O}_{4}$ matrix based on paraffin impregnated graphite electrode and electrochemical catalysis for trichloroacetic acid," Microchemical Journal, vol. 75, no. 1, pp. 51-57, 2003.

[24] S. Chandra, K. Arora, and D. Bahadur, "European Materials Research Society (EMRS) symposium on transport and photonics in Si-based nanomaterials and nanodevices-May 9-13, 2-11," Materials Science and Engineering B, vol. 177, no. 17, pp. 1523-1570, 2012.

[25] H. Xu, M. Shao, T. Chen, S. Zhuo, C. Wen, and M. Peng, "Magnetism-assisted assembled porous $\mathrm{Fe}_{3} \mathrm{O}_{4}$ nanoparticles and their electrochemistry for dopamine sensing," Microporous and Mesoporous Materials, vol. 153, pp. 35-40, 2012.

[26] B. Fang, G. Wang, W. Zhang, M. Li, and X. Kan, "Fabrication of $\mathrm{Fe}_{3} \mathrm{O}_{4}$ nanoparticles modified electrode and its application for voltammetric sensing of dopamine," Electroanalysis, vol. 17, no. 9, pp. 744-748, 2005.

[27] M. D. Shultz, J. Ulises Reveles, S. N. Khanna, and E. E. Carpenter, "Reactive nature of dopamine as a surface functionalization agent in iron oxide nanoparticles," Journal of the American Chemical Society, vol. 129, no. 9, pp. 2482-2487, 2007.

[28] C. $\mathrm{Xu}, \mathrm{K} . \mathrm{Xu}, \mathrm{H}$. Gu et al., "Dopamine as a robust anchor to immobilize functional molecules on the iron oxide shell of magnetic nanoparticles," Journal of the American Chemical Society, vol. 126, no. 32, pp. 9938-9939, 2004.

[29] C. Xu, K. Xu, H. Gu et al., "Nitrilotriacetic acid-modified magnetic nanoparticles as a general agent to bind histidine-tagged proteins," Journal of the American Chemical Society, vol. 126, no. 11, pp. 3392-3393, 2004.

[30] L. Wang, Z. Yang, J. Gao et al., "A biocompatible method of decorporation: bisphosphonate-modified magnetite nanoparticles to remove uranyl ions from blood," Journal of the American Chemical Society, vol. 128, no. 41, pp. 13358-13359, 2006.

[31] N. Kemikli, H. Kavas, S. Kazan, A. Baykal, and R. Ozturk, "Synthesis of protoporphyrin coated superparamagnetic iron oxide nanoparticles via dopamine anchor," Journal of Alloys and Compounds, vol. 502, no. 2, pp. 439-444, 2010.

[32] C. H. Liu, C. J. Yu, and W. L. Tseng, "Fluorescence assay of catecholamines based on the inhibition of peroxidase-like activity of magnetite nanoparticles," Analytica Chimica Acta, vol. 745, pp. 143-148, 2012.

[33] X. L. Zhao, Y. L. Shi, Y. Q. Cai, and S. F. Mou, "Cetyltrimethylammonium bromide-coated magnetic nanoparticles for the preconcentration of phenolic compounds from environmental water samples ," Environmental Science and Technology, vol. 42, no. 4, pp. 1201-1206, 2008.

[34] J. F. Smalley, K. Chalfant, S. W. Feldberg, T. M. Nahir, and E. F. Bowden, "An indirect laser-induced temperature jump determination of the surface $\mathrm{p} K_{a}$ of 11-mercaptoundecanoic acid monolayers self-assembled on gold," Journal of Physical Chemistry B, vol. 103, no. 10, pp. 1676-1685, 1999.

[35] S. Petrovic, "Cyclic voltammetry of hexachloroiridate(IV): an alternative to the Electrochemical Study of the Ferricyanide Ion," The Chemical Educator, vol. 5, no. 5, pp. 231-235, 2000.

[36] J. Zhao, L. Luo, X. Yang, E. Wang, and S. Dong, "Determination of surface $\mathrm{pK}_{a}$ of SAM using an electrochemical titration method," Electroanalysis, vol. 11, no. 15, pp. 1108-1111, 1999.

[37] R. K. Shervedani and M. Bagherzadeh, "Hydroxamation of gold surface via in-situ layer-by-layer functionalization of cysteamine self-assembled monolayer: preparation and electrochemical characterization," Electrochimica Acta, vol. 53, no. 22, pp. 6293-6303, 2008.

[38] X. Zhao, Y. Shi, T. Wang, Y. Cai, and G. Jiang, "Preparation of silica-magnetite nanoparticle mixed hemimicelle sorbents for extraction of several typical phenolic compounds from environmental water samples ," Journal of Chromatography A, vol. 1188, no. 2, pp. 140-147, 2008.

[39] H. Li, Q. Wei, J. He et al., "Electrochemical immunosensors for cancer biomarker with signal amplification based on ferrocene functionalized iron oxide nanoparticles," Biosensors and Bioelectronics, vol. 26, no. 8, pp. 3590-3595, 2011.

[40] L. X. Chen, T. Liu, M. C. Thurnauer, R. Csencsits, and T. Rajh, " $\mathrm{Fe}_{2} \mathrm{O}_{3}$ nanoparticle structures investigated by X-ray absorption near-edge structure, surface modifications, and model calculations," Journal of Physical Chemistry B, vol. 106, no. 34, pp. 8539-8546, 2002. 

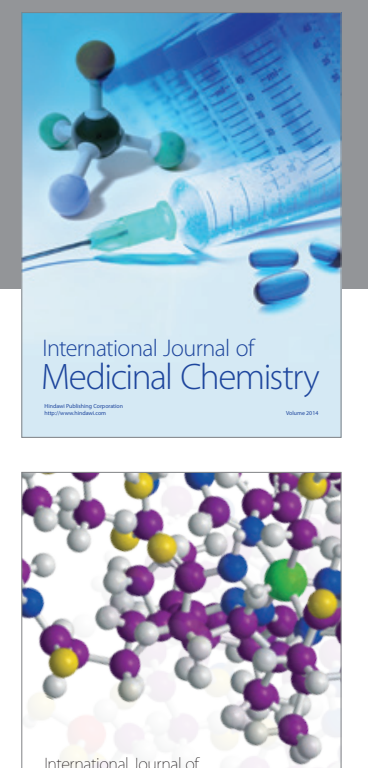

\section{Carbohydrate} Chemistry

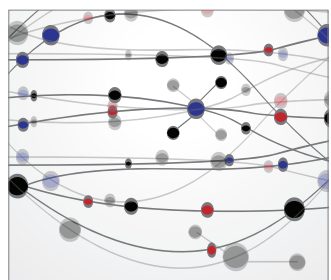

The Scientific World Journal
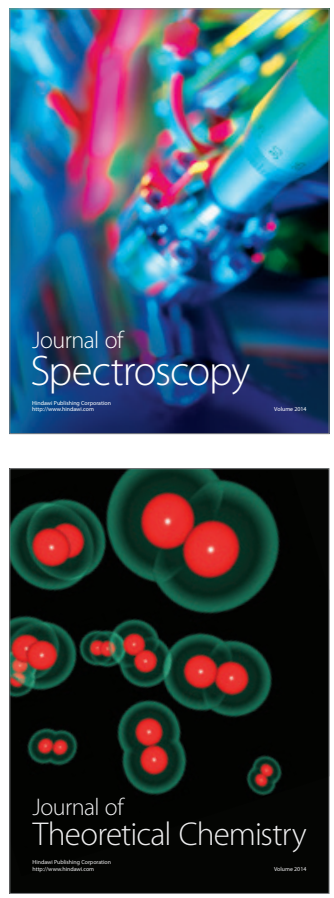
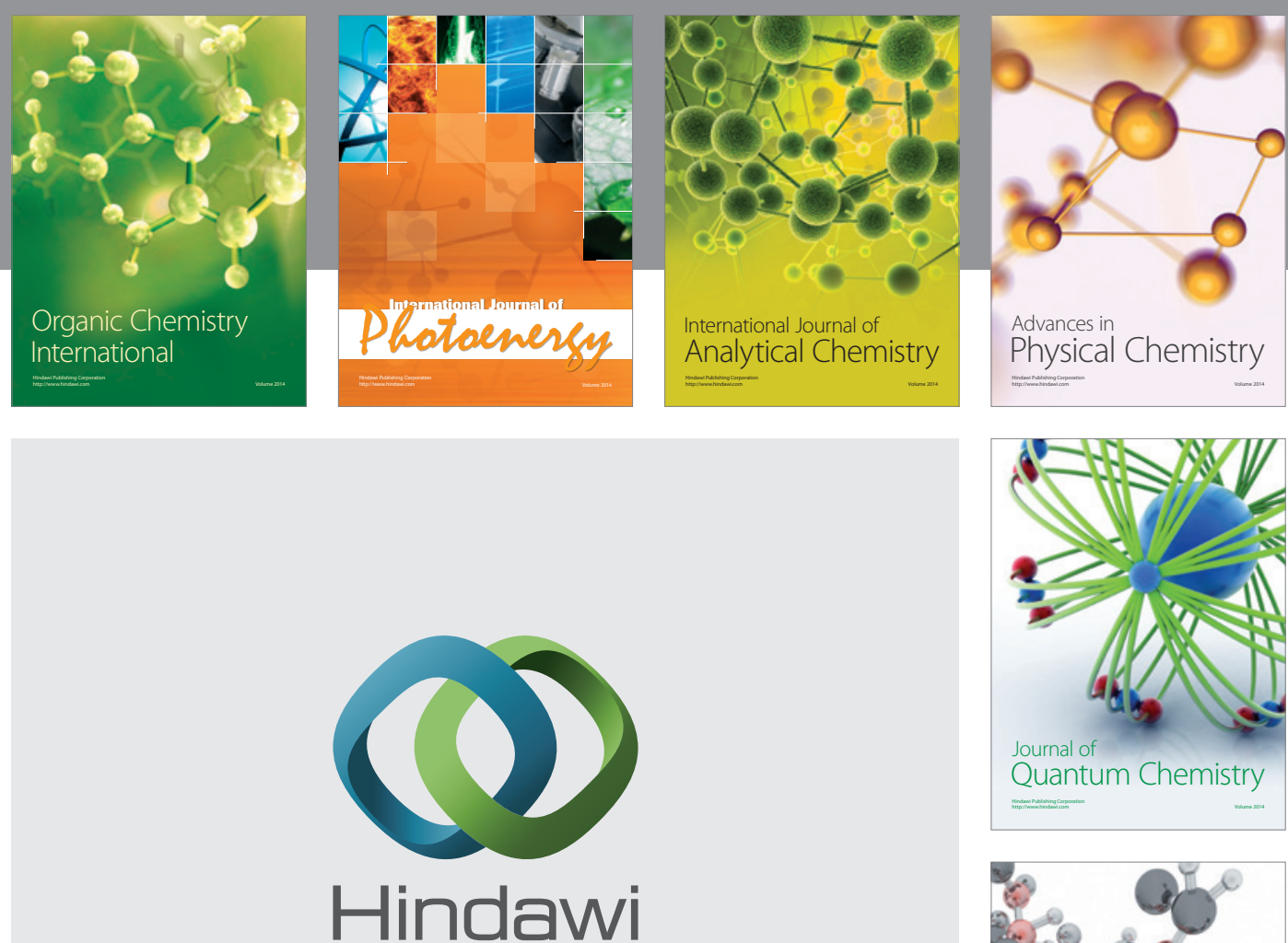

Submit your manuscripts at

http://www.hindawi.com

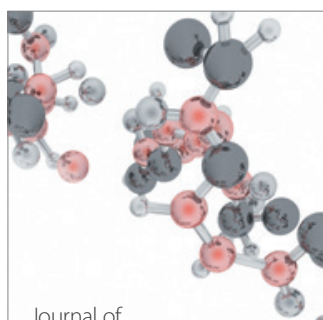

Analytical Methods

in Chemistry

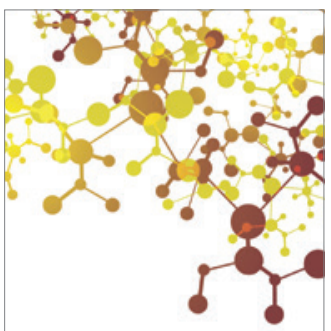

Journal of

Applied Chemistry

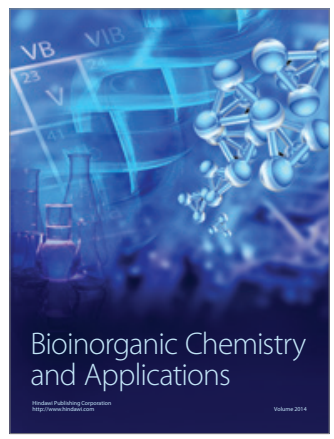

Inorganic Chemistry
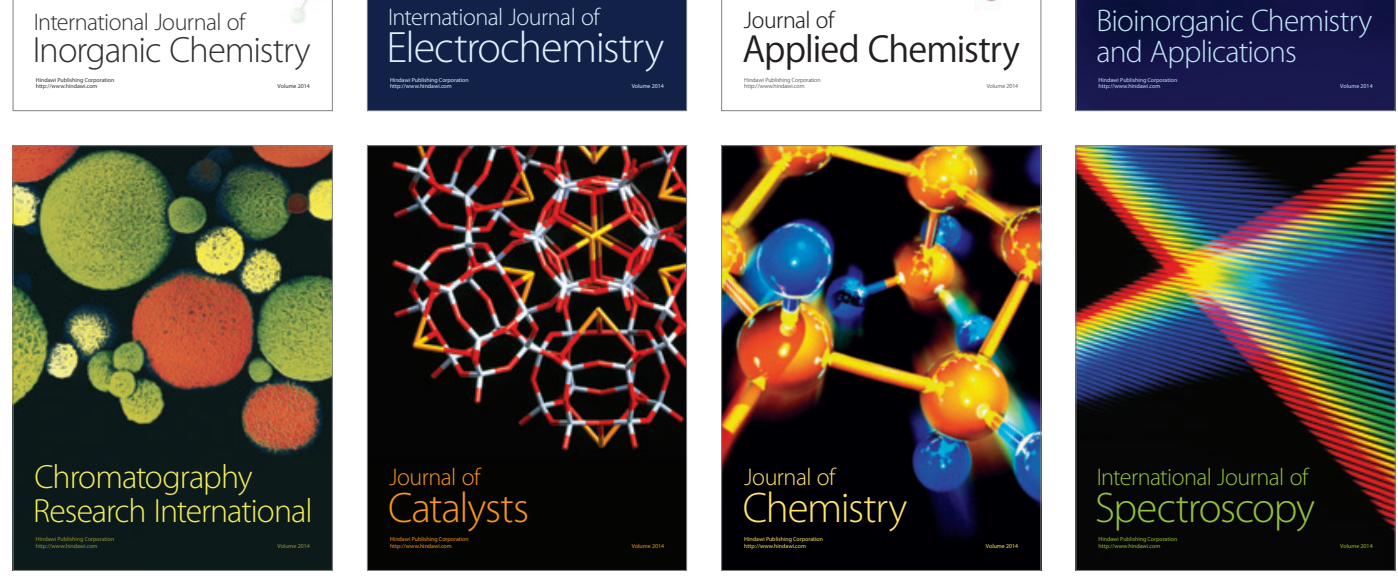